\title{
Erratum to: Discovery of the nonfunctional CYP2D6*31 allele in Spanish, Puerto Rican, and US Hispanic populations
}

\author{
Andrea Gaedigk • Maria Isidoro-García • Robin E. Pearce • Santiago Sánchez • \\ Virginia García-Solaesa • Carolina Lorenzo-Romo • Gloria Gonzalez-Tejera • \\ Susan Corey
}

Published online: 13 November 2010

(C) Springer-Verlag 2010

\section{Erratum to: Eur J Clin Pharmacol}

\section{DOI 10.1007/s00228-010-0831-4}

The article unfortunately contained a mistake.

The dosage of the patient is given as "Risperdal Consta (risperidone) $25 \mathrm{mg} /$ day, 15 days" on page 860 . It was incorrectly displayed and should read "Risperdal Consta (risperidone) $25 \mathrm{mg} / 15$ days".

The online version of the original article can be found at http://dx.doi. org/10.1007/s00228-010-0831-4.

A. Gaedigk $(\square) \cdot$ R. E. Pearce

Division of Developmental Pharmacology \& Experimental

Therapeutics, Children's Mercy Hospital and Clinics,

2401 Gillham Road,

Kansas, MO 64108, USA

e-mail: agaedigk@cmh.edu

M. Isidoro-García $\cdot$ V. García-Solaesa

Department of Clinical Biochemistry,

University Hospital of Salamanca,

Salamanca, Spain

S. Sánchez • C. Lorenzo-Romo

Department of Psychiatry, University Hospital of Salamanca,

Salamanca, Spain

G. Gonzalez-Tejera

Department of Psychiatry,

University of Puerto Rico School of Medicine,

San Juan, Puerto Rico

S. Corey

Department of Pharmacology \& Toxicology,

University of Puerto Rico School of Medicine,

San Juan, Puerto Rico 